\title{
Investigating the Effect of Enquiry-Based Learning Approach in Science on Junior High School 2 Students in Paradise International School
}

\author{
Kennedy Ameyaw-Baah, Charles Agyei Amoah, Yin Annafo, Humphrey Darkeh Assem \\ Tutor, Science Department, Wesley College of Education, Kumasi \\ Tutor, Science Department, OLA College of Education, Cape Coast \\ Tutor, Science Department, Wesley College of Education, Kumasi \\ Science Department, Wesley College of Education, Kumasi
}

\begin{abstract}
The purpose for this research was to compare any differences between enquiry-based learning methods and the traditional methods of teaching science in JHS 2. The study employed the Quasi-experimental research and action research methods under both quantitative and qualitative paradigms of research design. The selection of the school was done through purposive sampling method. The research participants were JHS 2 students $(\mathrm{N}=30)$ in two science classes at the research school. The traditional class was the control group. Two data collection instruments - Science Knowledge Assessment and Engagement checklist were used. It was found out that enquiry based teaching allow students to engage, discover, draw conclusions and report their findings increased their abilities to reason and problem solving. It was recommended that discussion in science should be the focus of enquiry based learning.
\end{abstract}

Keywords: Enquiry-based learning, teacher-centered approach, traditional method, instructional method.

\section{Introduction}

Educators and many advocates from the field of science have recognized the need for revising methods used for teaching science in schools in Ghana in order to improve student performance (Danso, 2010). Student scores are not the only concern in science education. Many science education researchers are concerned by the lack of depth of understanding of scientific concepts that students have exhibited for many decades (Anamuah-Mensah, \& Benneh, 2006).

The teaching methods used are not practical enough and that teachers make little effort to relate the concepts learnt and the examples/illustrations used to real life, especially within the context of the students' own lives and environment (Danso, 2010). Danso (2010) indicated that teachers favour teacher-centered, knowledge based teaching methods that leave little room for learners' participation. The most commonly used teaching methods at both basic and secondary levels have been found to be lecturing; question and answer; explanations of procedures and note giving, in that order (O'Connor, 2002). Little practical work is done due to shortage of equipment and consumables, and the development of a scientific way of thinking is abandoned in favour of the learning of nomenclature, definitions and stock standard procedures (O'Connor, 2002).

Learning science should not only involve memorisation and reasoning, but also performing activities and developing skills. The scientific approach to solving everyday problems need to be encouraged and developed in a formal educational setting... (Poon, Tan \& Tan, 2009).

The inquiry method of teaching which involves discovery, embraces this principle.

The Ministry of Education has developed new science models for teachers to integrate inquiry-based instruction into their science curriculum. New frameworks in recent school reforms call for higher standards in teaching successful reasoning and problem solving involves everyday life and produces lifelong learners. 


\section{Statement of the Problem}

In junior secondary schools in Ghana, students are not taught to view science as a form of knowledge concerned with understanding natural phenomena, leading to both knowledge validation and construction. In other words, the objectives of science instruction at all levels should be enquiry and construction of knowledge based on both the physical and biological environment (Fredua-Kwarteng 2015).

The goal of most junior high school science teachers is to create a learning environment that is conducive to teaching students the necessary concepts for academic achievement. For some teachers this focus on academic achievement does not extend beyond the walls of the classroom and the quizzes and tests given to students. High stakes testing has created a milieu that prevents students from seeing and understanding the applicability of science in the real world (Fredua-Kwarteng 2015).

The gravity of the educational situation should cause educators to take into more careful account the instructional methods they are using in their classrooms and be willing to change and adapt as the needs of their students change. The effectiveness of any science instructional approach must be investigated. If students do not perform well on assessments after being taught, then the use of such instructional methods in science should questioned/altered.

The general performance of the pupils in science is low and teachers often use traditional method instead of the advocated enquiry method. The JHS 2 pupils in particular need to improve their performance in science; the concerns of the staff are how to improve students' performance in this area. Report Card assessments from their previous term (as shown in table 1.1) showed that there is the need to bring in an intervention to help improve the performance in science among the pupils.

\section{Purpose of the Study}

The purpose for this research was to compare any differences between enquiry-based learning methods and the traditional methods of teaching science in JHS 2

\section{Research Questions}

1. What is the difference in achievement of students in science when they are taught with the enquiry based approach as compared to the traditional approach?

2. What is the level of engagement of JHS 2 students with the implementation of enquiry-based learning strategies as compared to the traditional approach?

\section{Methodology}

The study employed the Quasi-experimental research and action research methods under both quantitative and qualitative paradigms of research design. The selection of the school was done through purposive sampling method. The research participants were JHS 2 students $(\mathrm{N}=30)$ in two science classes at the research school. The traditional class was the control group. Students in the traditional class $(\mathrm{N}=15)$ included 8 females and 7 males. The enquiry class was the experimental group. Students in the experimental class $(\mathrm{N}=15)$ included 6 males and 9 females. The teaching intervention - enquiry based learning lasted 6 weeks in total as provided by existing science curriculum. The science teacher of the school implemented the teaching intervention. In general, all students share the same cultural and socio-economic background. Both classes have experienced the same traditional science teaching approach and had already finished 3 chapters from the prescribed science textbook.

In order to determine the effectiveness of using enquiry based learning strategies in science instruction on students $^{\text {ee }}$ achievement and level of engagement, two data collection instruments - Science Knowledge Assessment and Engagement checklist were used.

A pre-test was created by the teacher to assess studentse prior knowledge about physical science. The pre-test assessment was administered to students in both the traditional and enquiry groups in the first week of school prior to week 1 of the research study. The questions were developed based on the science curriculum for JHS 2 students and were administered to both classes using identical verbal instructions.

Field note observations were used to record scores on the students ${ }^{\text {ee }}$ engagement checklist. The scores were written on the checklist for each student. Students who were fully engaged and remained on task were given a score of two. Students who were engaged in the task with very little deviation were given a score of one. The students who were frequently off task and had to be redirected back to the task were given a score of zero. Each student in the traditional class was assigned a number 1T through 15T while each student in 
the enquiry class was assigned a number 1EB through 15EB. The corresponding numbers were used by the teacher and researcher to identify students in the field notes and on the engagement checklist. Field notes were recorded by the teacher and researcher about comments, questions asked, behaviours and attitudes of participating students. Behaviours noted in the field notes were categorized according to themes and patterns to determine whether students in the enquiry class were more engaged in the learning process versus the level of engagement of students in the traditional class. Percentages of on-task behaviours were compared with off-task behaviours to determine whether the enquiry based learning method of teaching significantly affected students' engagement in science.

The following two treatments were used in the study:

a. Taught by using enquiry learning (experimental group).

\section{b. Taught by using traditional method (control group).}

Both groups were instructed by the same science teacher. Before the implementation of treatment the teacher was informed about the purpose of the study and enquiry based instruction. In order to check the implementation of both treatments in control and experimental groups, classroom observations were carried out. During the process of observation, the interaction between teacher-students and students-students; participation and contribution of students into learning environment; behaviour and attitude of students and teacher as well as the physical conditions and material availability of the classroom were observed. Before observation of the real implementation process, researcher visited the classrooms twice, sat silently at the back and observed classroom. Students in the experimental group were taught with enquiry based instruction. In the instruction based enquiry method, teaching and learning activities and lesson plans were designed to maximize students ${ }^{\text {ee }}$ active involvement in the learning process. The topics included in the lesson plans were from three units of JHS 2 sciences book; they included: hidden strangles (microbes, viruses, diseases, body's defenses ways, helping the defense of the body, and vaccines); physical changes, humans and their and environment.

Activities and lesson plans in enquiry group were implemented by considering the $5 \mathrm{E}$ cycle of enquiry learning. In the engagement phase, teacher tried to increase studentse ${ }^{\text {ee }}$ attention, get them interested and ready to learn. So that students had opportunities to make some connections between prior knowledge and present learning experiences so that their thinking was organized toward learning out comes. Students had previous knowledge about the concepts like microbes, viruses, diseases and vaccines. An interesting image symbolizing the body's defenses system was presented to the students. In addition, a story about the relationship among the microbes, viruses and body's defenses system was read. In the exploration phase, intention was to create learning environments for students so that they could observe scientific processes, record data, isolate variables, design and plan experiments, create graphs, interpret results, develop hypotheses, and organize their findings. Teacher only provided questions, suggested approaches, gave feedbacks, and assessed understandings. Microbe structure was examined under the microscope in the following class. Activities used in the explanation phase helped students demonstrate their understanding of related concepts. Teacher guided students toward coherent and consistent generalizations, helped students with distinct scientific vocabularies, and provided questions that helped students use these vocabularies to explain the results of their explorations. Activities used in elaboration phase, provided an opportunity for students to apply their knowledge to new domains, which may include raising new questions and hypotheses to explore. A research task about the importance of vaccines was given in elaboration stage. With the activities used in the evaluation phase students had opportunity to assess their understanding and abilities. The activities in evaluation phases were also used by teacher for both formative and summative evaluations of student learning.

In the control group, a teacher directed strategy representing the traditional approach was used. The teacher used direct teaching and question and answer methods to teach related topics and basic concepts. Basic explanations and question and answer methods suited. Both traditional and enquiry classes used the same textbook and handouts.

\section{Results/Discussion}

Student's pre-test results are presented in table 1.

Table 1: Means, Standard Deviations and Standard Error Mean of the Experimental and Control Groups for Pre-tests scores in academic achievement test 


\begin{tabular}{|c|c|c|c|c|}
\hline Variable & Group & $\begin{array}{l}\text { Number of } \\
\text { Students }\end{array}$ & $\begin{array}{l}\text { Mean Standard } \\
\text { Deviation }\end{array}$ & $\begin{array}{c}\text { Standard Error } \\
\text { Mean }\end{array}$ \\
\hline \multirow{2}{*}{ Pre-test } & $\begin{array}{l}\text { Enquiry instruction } \\
\text { (Experimental) }\end{array}$ & 15 & $\begin{array}{l}8.53 \\
1.11\end{array}$ & 4.30 \\
\hline & $\begin{array}{l}\text { Traditional instruction } \\
\text { (Control) }\end{array}$ & 15 & $\begin{array}{l}8.12 \\
1.05\end{array}$ & 4.08 \\
\hline
\end{tabular}

In order to answer the first research question, on the differences between enquiry learning approach on students $^{\text {ee }}$ achievements and the traditional approach, students' pre -test achievement results were collected. Means, Standard Deviations and Standard Error Mean of the Experimental and Control Groups for Pre-tests scores in academic achievement test were calculated.

Students' post-test results are presented on table 2.

Table 2: Means, Standard Deviations and Standard Error Mean of the Experimental and Control Groups for post-tests scores in academic achievement test.

\begin{tabular}{|c|c|c|l|l|}
\hline Variable & Group & $\begin{array}{l}\text { Number of } \\
\text { Mean Students }\end{array}$ & Standard Deviation & $\begin{array}{l}\text { Standard Error } \\
\text { Mean }\end{array}$ \\
\hline \multirow{3}{*}{ Post-test } & $\begin{array}{l}\text { Enquiry } \\
\text { Instruction } \\
\text { (Experimental) }\end{array}$ & 15 & $\begin{array}{l}16.40 \\
2.92\end{array}$ & 0.84 \\
\cline { 2 - 5 } & $\begin{array}{l}\text { Traditional } \\
\text { instruction } \\
\text { (Control) }\end{array}$ & 15 & 9.0 & 3.15 \\
\hline
\end{tabular}

Comparisons of Pre-test and Post-test Results for Traditional Instruction and Enquiry-Based Instruction

Paired samples t-test was conducted to compare the enquiry instruction and the traditional instruction and the results are presented on table 3

Table 3: Paired t-test comparison on enquiry instruction and traditional instruction 


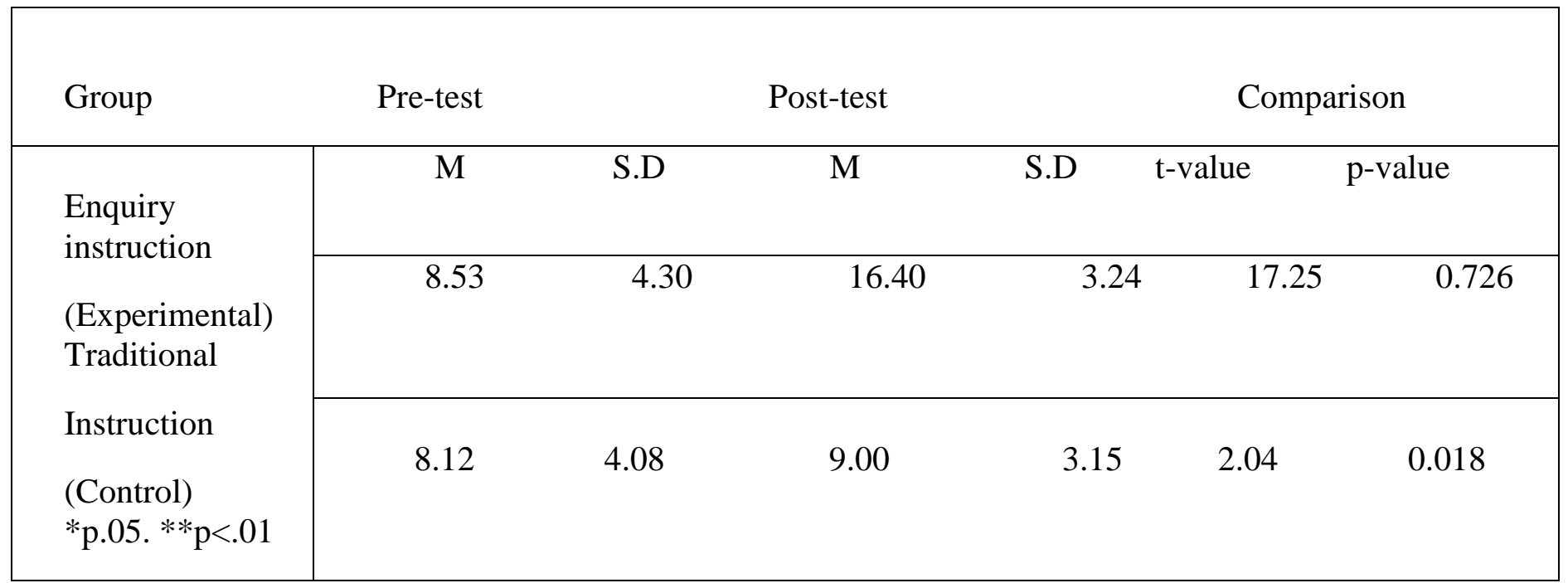

From table 3, Paired samples t-tests indicated that the enquiry instruction group made significant gains from pre-test to post-test while that of the traditional group is almost negligible.

Table 4: Comparison of Mean Gains

\begin{tabular}{|c|c|c|c|c|c|c|c|c|}
\hline Group & Pre-test M & Post-test M & \multicolumn{6}{|c|}{ Gains } \\
\hline Enquiry & & & Mean & & -value & & $\mathrm{p}$ & \\
\hline $\begin{array}{l}\text { Instruction } \\
\text { Traditional }\end{array}$ & 8.53 & 16.40 & 7.87 & & 0.93 & & 4.83 & \\
\hline $\begin{array}{l}\text { Instruction } \\
\text { (control) }\end{array}$ & 8.12 & 9.00 & & 0.88 & & -1.4 & & 0.001 \\
\hline
\end{tabular}

\section{Student Engagement Results}

The level of students ${ }^{\text {ee }}$ engagement was calculated in percentage. Field notes recorded during intervention indicated that students were more engaged, focused, and on task in enquiry based learning group than traditional group.

Table 5: Students Engagement Result

\begin{tabular}{|lccc|}
\hline Group & Fully Engaged & Engaged & Not Engaged Enquiry \\
Instruction & & & \\
(Experimental) & $87 \%$ & $13 \%$ & \\
Traditional Instruction & & & $53 \%$ \\
(Control) & $20 \%$ & $27 \%$ & \\
\hline
\end{tabular}

\section{Discussion of Results}

The Effects of Enquiry-Based Learning Strategies on JHS 2 Students' Achievement Scores 
With regard to the first research question, the effectiveness of enquiry as instructional strategy on students $^{\text {ee }}$ academic achievements, results clearly indicated greater academic achievement among the experimental group. This result is not unique, however several studies support the superiority of the enquiry based learning as an instructional strategy over the traditional education (Khan et al. 2011; Opara 2011; Barthlow 2011). Enquiry learning, as a constructivist teaching strategy, fosters students ${ }^{\text {ee }}$ higher order thinking skills while they are engrossed in solving problems and thinking critically as well as verifying and refining concepts such as in biology. This way of instruction allows students to develop meaningful scientific knowledge, build their own conceptualizations about science and scientific knowledge as well as actively learn, with ample time, while grappling with objective-based question(s) rather than reciting and dispensing knowledge on a spoon feeding way. Moreover, spending appropriate time on an optimal learning cycle for understanding questions, searching for answers, explaining findings, forming and testing hypothesis, making inferences and all in social communicated group work will prompt students' optimal level of cognition and skills and expose them to the normal scientists' work. There are generally two main goals of Science education in Ghana. First, it inculcates scientific literacy and culture for all, so that people can make informed choices in their personal lives and approach challenges in the workplace in a systematic and logical order. Second, it aims to produce competent professionals in the various scientific disciplines who can carry out research and development at the highest level. For meaningful scientific education, it is important for pupils to be trained in the investigative process of seeking answers to problems .This requires pupils to physically explore and discover knowledge within their environment and in the laboratory to be able to contribute new scientific principles and ideas to the body of knowledge already existing in their culture.

With these well laid down plans, one would expect Ghanaian students to perform well in science subject but this is not the case. According to a TIMSS (2013) report, Ghana ranked 46th on the international benchmark in science. Only $13 \%$ and $3 \%$ of Ghanaian students reached the low and intermediate international benchmarks respectively.

Over $80 \%$ of the students not reaching the low international benchmark imply that majority of our students have poor knowledge of basic science facts and weak grasp of science concepts and enquiry skills which are lower level cognitive competencies. No student reached the high or advanced international benchmarks in science (TIMSS, 2013). Promoting enquiry-based learning will help improve students' grades greatly. Pertinent information was gained through the data collection for the current research study about the effects of enquiry-based learning in science on JHS 2 student. The findings from the pre-test show that the students involved in the study show low performance and therefore have difficulty in remembering and linking what they had been taught earlier. From table 1, the mean score of the enquiry instruction group was 8.53 and that of the traditional instruction group was 8.12. It was clear there was no significant difference between students $^{\text {ee }}$ average scores in the control and experimental groups at the beginning of the study.

However, the findings from post-test show that the students who were taught science through the use of enquiry based performed creditably well than students who were instructed through the traditional lecture method. From table 2 there was significant difference between students' average scores in the inquiry groups mean (16.40) score and that of the traditional group (9) after the interventions where put in place of the study.

The mean score for inquiry group had increased from 8.53 (pre-test) to 16.40 (post test), with a mean gain of 7.87. The mean gain of the traditional group was only 0.88 .

The students from the experimental group performing well in the post test after the intervention as compared to the performance of the students from the control group confirms the studies of Ergul et al. (2011), Khan and Iqbal (2011), which show that there was statistical significant difference between students who were taught Physics and Biology through the use of an enquiry-based lesson than those students who were taught with the traditional lecture method. These previous studies as well as the current study show that the students from the experimental groups outperformed their counterparts from the control group. Hence, the use of enquiry based learning helps to improve the performance of students in science.

\section{Improvement in Levels of Engagement of JHS 2 Students}

Extent of student participation in the teaching-learning process was observed by TIMSS (2003) among JHS students. About $73 \%$ of students observed indicated that they watched the teacher demonstrate an experiment/investigation, $75 \%$ reported that they were made to relate what is being taught in science to 
their daily lives TIMSS (2003). More than two thirds said that they were asked to write explanations about what was observed and why it happened. There seemed to be reasonable emphasis on performance of enquiry activities (experiments/investigations) TIMSS (2003). There seemed to be more emphasis on demonstrations instead of group work and students performing their own experiments/investigations. Teachers of $46 \%$ of JSS students reported asking their students to watch them demonstrate an experiment/investigation in at least half of the lessons (TIMSS 2003). Teachers of about $40 \%$ of the students reported having their students design or plan experiments/investigation and write explanations about what was observed and why it happened (40\%). Teachers of majority of the students (91\%) reported getting students to relate what they learn in science to their daily lives (TIMSS 2003).

In order to determine the effect of enquiry based learning strategies on students ${ }^{\text {ee }}$ engagement during the intervention period, the teacher and the researcher implemented a Student Engagement Checklist. The checklist was used three times each week during the 6-week intervention period for the traditional and the enquiry groups. Students who were fully engaged and participated in all aspects of the lesson activities earned a score of two for the class period. To be considered fully engaged a student was observed paying attention in classroom discussions, participating in classroom discussions, completing assigned reading, and being actively involved in group work. Students who were engaged and participated in the lessons with not more than one redirection from the teacher earned a score of one. Students who had to be frequently redirected by the teacher to properly participate exhibited out of seat behaviour, talked, daydreamed, and played with materials in a way they were not intended earned a score of zero and were examples of not being engaged in the lesson. Of the 15 students in the traditional class, 3 exhibited full engagement $20 \%$ of the time. The enquiry based group, also with 15 students, had approximately $87 \%$ full engagement, which was 13 students. As shown in Table 5, students who received the enquiry based learning intervention exhibited greater engagement behaviours than students who participated in the class with traditional instruction.

Field notes recorded during enquiry based intervention indicated that students were more engaged, focused, and on task. The enquiry based learning students engaged daily in problem-solving discussions that led them to complete tasks quickly and with little redirection from the teacher. Comments such as, "This is fun," and "Oh, I see how you do it!" were noted from students in the enquiry based learning group indicating an excitement about solving a problem through discovery. The enquiry based learning students participated in more brainstorming and sharing of ideas during small group time, as students worked together as partners to solve problems. Entries from student journals revealed a high level of understanding about science concepts. Students wrote more detailed journal entries, which indicated a higher level of understanding and engagement. Overall, a higher level of student engagement was observed in the enquiry based learning group.

Field notes recorded during the traditional instruction time indicated that students did not engage in as much idea sharing about science and had to be frequently redirected back to the task and discussions. Students frequently did not follow directions, which resulted in a loss of instructional time.

In the study, the students actively constructed their own meaning of the concepts being taught by interacting with materials, questioning ideas and linking information. This implies that students should appreciate the fact that they need to construct their own meaning of scientific material whenever it is presented to them (Gallagher, 2000). Further in the enquiry instruction, students were grouped, made to interact with materials, and communicate among group members. This enhanced the studentse understanding and hence their improved performance. This could be attributed to the fact that social constructivists share the view that meaning is co-constructed before it is internalized; and this is achieved through students ${ }^{\text {ee }}$ communication among themselves as they actively interact with materials (Woolfolk, 2007). JHS science teachers are therefore encouraged to adapt enquiry-based lessons in teaching science where students can communicate among themselves on scientific material; and learn from each other.

Students in the experimental group were actively engaged either physically or mentally in learning situations. On the contrary, students in the control group were passively listen to lectures or followed steps in laboratory manual instructions as a cook book in order to accomplish their tasks. This active, self-directed environment embraces not only acquiring the concepts or the content knowledge but also skills in how to "approach a problem, identify important resources, both design and carry out hands on investigations, analyze and interpret data, and, most importantly, recognize when they have answered the question or solved 
the problem" (Matyas 2000). In addition, enquiry learning, as a supportive environment, promotes students ${ }^{\text {ee }}$ highest and best skill level, which is the optimal level of performance, more than the functional level (Barthlow, 2011). What is striking, in such student-centered learning environments, is that students learn to prioritize information, and decide which is most important and which is least helpful especially in this increasingly vast information era (Matyas, 2000).

Communication skills amongst students and social work are also in the light, in terms of the group work during guided enquiry sessions. Students in the experimental group used to learn how to distribute tasks on the group members for the sake of one object, which may be solving a problem or answering work sheet questions. Many studies advocate learning through social-constructivist environments in regard of the better academic achievements, science literacy positions, self-confidence and research competences (Brickman et al. 2009; Opara 2011). Evaluation of the formative and summative worksheets reflects clearly the effectiveness of the group work. Lee et al., (2010) and Bilgin (2009) reported the fruition of the group work in the guided inquiry classes especially in the lab sessions. What was striking, that the teacher's greatest efforts during the enquiry activities and classes were mainly directed to supervise, guide and maintain students ${ }^{e e}$ tasks in scientific investigations more than to control and manage students ${ }^{e e}$ behavioral issues, as it is the situation in normal laboratory lessons. Although enquiry-group work classes are generally characterized with activism and dynamism, students in these classes were seemed to be more motivated and attached to their tasks. Many studies have emphasized these growing positive attitudes towards learning sciences through enquiry instructional strategy (Chang \& Tasi 2005; Taraban et al. 2007; Bilgin 2009).

\section{Conclusion}

It is concluded that enquiry based teaching allow students to engage, discover, draw conclusions and report their findings increased their abilities to reason and problem solve. As students participated in enquiry-based learning, they gradually learned to investigate, reason, and organize knowledge and then to incorporate that knowledge into their understanding without intervention from their teacher. The current research study challenged the teacher to relinquish control of the science lesson content information and allow students to control participation in their own acquisition of knowledge and develop higher-order thinking skills.

\section{Recommendations}

1. If a teacher wants to make a difference in the performance of their students towards science, they themselves must be willing to change and adapt. The inquiry approach is very malleable and allows for a multitude of approaches, but it is essential that the teacher find creative ways to do so. Teachers must be prepared to change.

2. Discussion in science should be the focus of enquiry. By doing this, students gain higher order cognitive skills that helps them see the links to search for answers. Verbalizing the problem also provides students with models to apply successful strategies

\section{References}

[1] Anamuah-Mensah, J. \& Benneh, B. (2006). Particular issues of teacher education in Ghana. The UNESCO Teacher Training Initiative for Sub-Saharan Africa, Accra: Ghana

[2] Barthlow, M. (2011). The Effectiveness of Process Oriented Guided Inquiry Learning To Reduce Alternative Conceptions In Secondary Chemistry. Ph.D. Thesis. Liberty University.

[3] Bilgin, I. (2009). The Effects of Guided Inquiry Instruction Incorporating a Cooperative Learning Approach on University Studentse Achievement of Acid and Bases Concepts and Attitude Toward Guided Inquiry Instruction. Journal of Scientific Research and Essay, Vol. 4 (10), pp. 1038-1046.

[4] Brickman, P., Gormallt, C., Armstrong, N. \& Hallar, B. (2009). Effects of Inquiry-Based Learning on Studentse Science Literacy Skills and Confidence. International Journal for the Scholarship of Teaching and Learning. Vol. 3 (2), pp. 1-22.

[5] Chang, C.Y. \& Tsai, C.C. (2005). The Interplay Between Different Forms of CAI and Students ${ }^{\text {ee }}$ Preferences of Learning Environment in the Secondary Science Class. Science Education, Vol. 89 (5), pp. 707-724. 
[6] Danso, J. B. (2010). Evaluation of inclusive education practice in Ghana: Survey of inclusive pilot schools. Thesis submitted to the Department of Educational Foundation, Faculty of Education, University of Cape Coast, in partial fulfillment of the requirements for the award of Master of Philosophy in Special Education, Cape Coast: Ghana

[7] Ergul, R., Simsekli, Y., Calis, S., Ozdilek, Z., Gocmencelebi, S. \& Sanli, M. (2011). The effects of inquiry-based science teaching on elementary school students ${ }^{\text {ee }}$ science process skills and science attitudes. Bulgarian Journal of Science and Education Policy, 5, 48-68.

[8] Fredua-Kwarteng, (2015). Ghana Flunks Math and Science: Analysis. Retrieved from http://webcache.googleusercontent.com/search.

[9] Gallagher, J. J. (2000). Teaching for understanding and application of science knowledge.

[10] School Science and Mathematics Journal, 100(6), 310-316.

[11] Khan, M., \& Iqbal, M. Z. (2011). Effect of inquiry lab teaching method on the development of scientific skills through the teaching of Biology in Pakistan. Language in India: Strength for Today and Bright Hope for Tomorrow, 11(ISSN 1939-2940), 169-178.

[12] Lee, H., Linn, M., Varma, K. \& Liu, O. (2010). How do Technology-Enhanced Inquiry Science Units Impact Classroom Learning? Journal of Research in Science Teaching, Vol. 47, pp. 90.

[13] Matyas, M. (2000). Teaching and Learning by Inquiry. The American Physiological Society. Ben BiosciEdNet.

[14] O'Oconnor, J. P. (2002). Teachers are the problem in SMT, not girls. Retrieved from http://www.adea.org

[15] Opara, J. (2011). Inquiry Method and Student Academic Achievement in Biology: Lessons and Policy Implications. American-Eurasian Journal of Scientific Research, Vol. 6 (1), pp. 28-31.

[16] Poon, C., Tan, D., \& Tan, A. (2009). Classroom management and inquiry-based learning: Finding the balance. Science Scope, 32 (9), 18-21. (EJ850038).

[17] Taraban, R., Box, C., Myers, R., Pollard, R. \& Bowen, C. W. (2007). Effects of Active Learning Experiences on Achievement, Attitudes, and Behaviors in High School Biology. Journal of Research Science in Teaching. Vol. 44 (7), pp. 960-979.

[18] TIMSS (2003) International Science Report Findings from IEA ${ }^{\text {ees }}$ Trends in International Mathematics and Science. Ghanaian JSS2 Students' Achievement in Mathematics and Science: TIMSS-2003. Retrieve from http://timss.bc.edu/isc/publications.html

[19] Woolfolk, A. (2007). Educational psychology (10th ed.). New York: Pearson Education, Inc. 